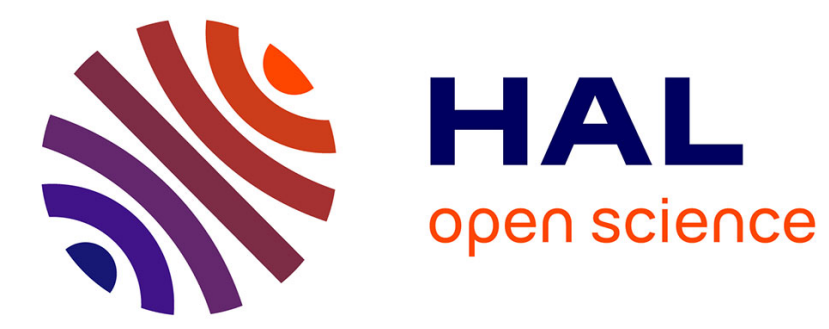

\title{
A review of negative ion sources
}

\author{
R. Middleton
}

\section{To cite this version:}

R. Middleton. A review of negative ion sources. Revue de Physique Appliquée, 1977, 12 (10), pp.14351444. 10.1051/rphysap:0197700120100143500 . jpa-00244343

\section{HAL Id: jpa-00244343 https://hal.science/jpa-00244343}

Submitted on 1 Jan 1977

HAL is a multi-disciplinary open access archive for the deposit and dissemination of scientific research documents, whether they are published or not. The documents may come from teaching and research institutions in France or abroad, or from public or private research centers.
L'archive ouverte pluridisciplinaire HAL, est destinée au dépôt et à la diffusion de documents scientifiques de niveau recherche, publiés ou non, émanant des établissements d'enseignement et de recherche français ou étrangers, des laboratoires publics ou privés. 


\title{
A REVIEW OF NEGATIVE ION SOURCES $\left(^{*}\right)$
}

\author{
R. MIDDLETON \\ Physics Department, University of Pennsylvania, \\ Philadelphia, Pennsylvania 19104. U.S.A.
}

\begin{abstract}
Résumé. - Nous passerons rapidement en revue l'état actuel des sources d'ions négatifs et leur compatibilité avec des accélérateurs tandem. Les récents développements des sources à sputtering de caesium seront discutés en détail, en particulier des points tels que : la forme optimum du cône, l'utilisation de gaz pour augmenter le courant d'ions négatifs soit de l'élément, soit de l'espèce moléculaire, les avantages et les inconvénients d'utiliser le faisceau de caesium réfléchi et la possibilité d'utiliser des alliages de métaux alcalins comme cible de sputtering. Nous arriverons a l'évidence que, à l'exception de quelques gaz rares, un but non irréaliste est d'obtenir un courant minimum de $1 \mu \mathrm{A}$ pour tous les éléments. Finalement nous donnerons un bref compte-rendu de l'accélération du tritium à travers l'accélérateur FN de l'université de Pennsylvanie.
\end{abstract}

Abstract. - A brief review of the present status of negative ion sources and their compatability with tandem accelerators will be presented. Recent developments of the caesium beam sputter source will be discussed in some detail including topics such as, the optimum shape of the sputter cone, the use of gases to increase either the elemental negative ion current or that of a molecular species, the advantages and disadvantages of using the reflected caesium beam and the possibility of using alkali metal alloys as sputter targets. Evidence will be presented that, with the exception of some of the noble gases, a not unreasonable goal is a minimum negative ion current of $1 \mu \mathrm{A}$ for all elements. Finally a brief account will be given of the successful acceleration of tritium through the university of Pennsylvania's F.N. tandem accelerator.

1. Introduction. - Thanks to a number of major developments occuring during the past 5 or 6 years the present status of negative ion sources is extremely good. The prospects appear really very excellent for attaining $1 \mu \mathrm{A}$ or better of high quality beams for all but a handful of elements, notably the noble gases and even here the situation is not entirely hopeless. Last year at the University of Pennsylvania we generated negative ion beams from some 50 different elements using a sputter source and from the periodicity of the results it is clear that the number can be greatly expanded. Although currents frequently were less than the $1 \mu \mathrm{A}$ plus goal there are many indications that these can be substantially increased.

Currently there' are three promising methods for producing negative ion beams and these can be loosely classified under the headings : charge exchange, direct extraction and caesium beam sputtering. I will begin by discussing briefly the first two of these and then discuss at some length the caesium beam sputter process and conclude with a brief description of our tritium acceleration program.

2. Charge Exchange. - A few years ago charge exchange was the dominant method for producing negative ions but recently it has fallen into less com-

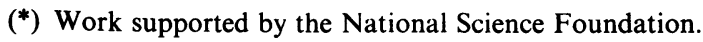

mon use with the exception that it remains the sole method for making $\mathrm{He}^{-}$ions. Later this morning we will hear of the exciting charge exchange cross section measurements of Heinemeier and Tykesson $[1,2]$ in alkali and alkaline earth metal vapours. Figure 1 shows some of their cross section measurements for a variety of ions passing through a sodium vapour adder canal. It will be observed that these are surprisingly large and negative ion conversion efficiencies frequently approach and sometimes exceed $10 \%$.

These results coupled with the vast amount of effort that is being currently expended on the development of diverse and intense positive ion sources, particularly for ion implantation, strongly suggest that charge exchange is far from an obsolete method for producing negative ions. Indeed in spite of the relatively low cross sections for the formation of alkali metal negative ions this may prove the most effective production process, since intense positive ion beams of the latter can be readily generated in simple and reliable surface ionization sources.

Also of interest is the relatively large cross section for the formation of $\mathrm{Be}^{-}$ions. These, like the negative ions of $\mathrm{Mg}$ and $\mathrm{Ca}$, are known to be metastable and are probably formed by a two-step process. It is speculated that if double negative ions exist they may well be formed in a similar fashion and the charge 


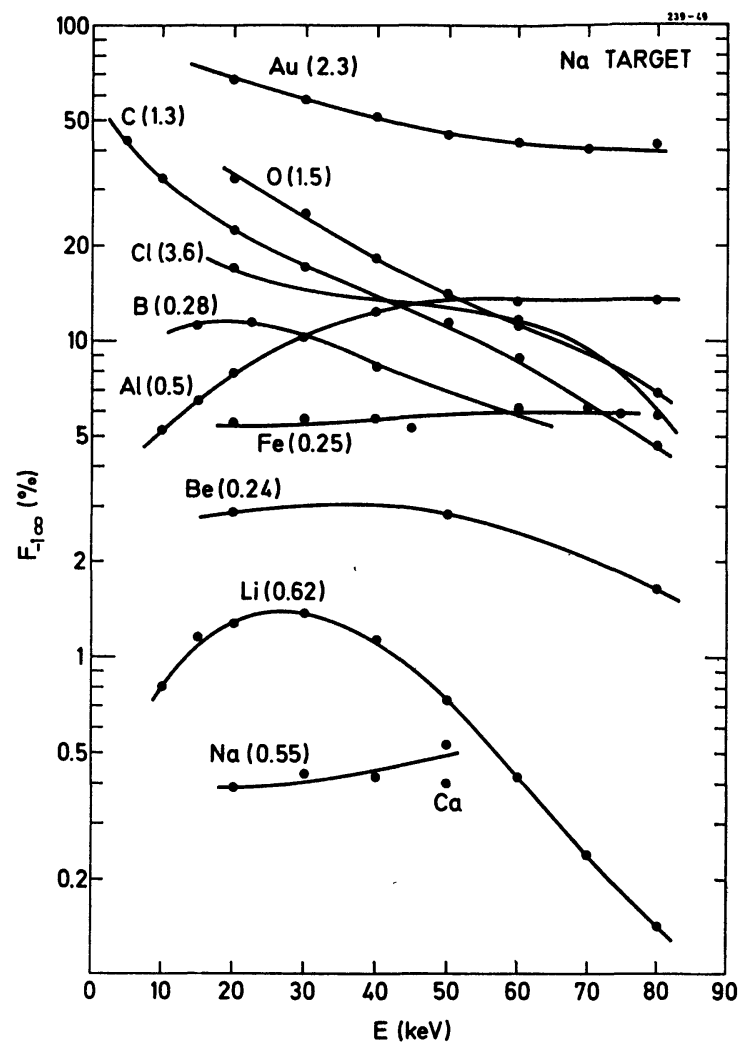

FIG. 1. - Measured negative equilibrium charge-state fractions for various ions passing through sodium vapour. Results obtained by

J. Heinemeier and P. Tykesson, University of Aarhus.

exchange technique may provide a promising method for creating them.

3. Direct Extraction. - The superior emittance and high brightness of the direct extraction duoplasmatron will undoubtedly ensure its continued use for many years to come, particularly with relatively light ions such as $\mathrm{H}^{-}, \mathrm{O}^{-}, \mathrm{F}^{-}$and $\mathrm{Cl}^{-}$. However, it does not have the flexibility of the Penning sources developed by Heinicke, Bethge and Baumann [3] and more recently by Tykesson, Andersen and Heinemeier [4]. The latter source is of particular interest since it has a novel secondary sputter cathode and negative ion formation is significantly enhanced by the introduction of caesium vapour into the arc chamber. A schematic representation of this source, which was developed at Aarhus, is shown in figure 2.

As of the 1976 Gatlinburg Heavy Ion Source Conference the performance of this source, particularly for heavier ions, was very good and held considerable promise for the future. For example $6 \mu \mathrm{A}$ of $\mathrm{Ni}^{-}$ were reported, $30 \mu \mathrm{A}$ of $\mathrm{Cu}^{-}, 3 \mu \mathrm{A}$ of $\mathrm{Ta}^{-}$and $80 \mu \mathrm{A}$ of $\mathrm{Au}^{-}$. The emittance of the source was measured by Doucas, Greenway, Mck. Hyder and Knox [5] and, although it is inferior to that of a direct extraction duoplasmatron, it is generally comparable with that of a caesium beam sputter source.

4. Caesium Beam Sputter Sources. - During the past year or two, several laboratories have expended considerable effort to improve and expand the flexibi-

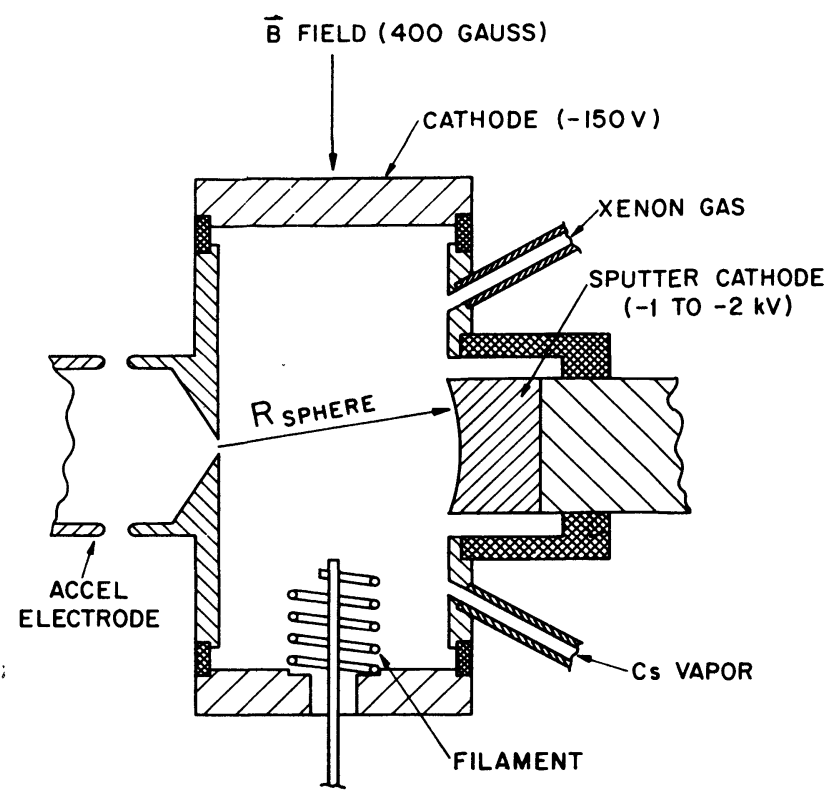

FIG. 2. - A schematic representation of the Penning sputter source developed by P. Tykesson, H. H. Andersen and J. Heinemeier, University of Aarhus [ $\left.{ }^{4}\right]$.

lity of the caesium beam sputter source. We will hear later in this session of the work at Minnesota and at McMaster to adapt the source for tritium acceleration, of the work at Bochum on using the reflected caesium beam, of the production of beams of ${ }^{48} \mathrm{Ca}$ and other rare isotopes at Munich and about experiences with an inverted sputter source in Athens. In view of these and a description of a pulsed sputter source in Zurich it is perhaps appropriate for me to confine myself to some recent developments at the University of Pennsylvania.

Figure 3 shows a sectional drawing of the source that we have adopted as a general work horse - an identical source was used in our tritium program. It is modular in construction and can be rapidly disassembled, cleaned and re-assembled with highly reproducible accuracy. The cone wheel has provision for 18 cones and these can be changed without a major strip-down. It will be noticed that we do not use an einzel lens to focus the caesium beam as was first introduced by Doucas, Mck. Hyder and Knox [6] but we have been able to obtain a comparable caesium spot size of about $2 \mathrm{~mm}$ [7] by minimizing the distance between the ionizer and the cone and by recessing the ionizer a short distance behind the ground electrode. The system is effective but lacks the useful steering action of the split einzel lens introduced by Purser of General Ionex Corporation. Negative ions are usually extracted by an electrode at ground potential but on occasions this has been positively biased to improve the focus of the reflected caesium beam. A gridded einzel lens is located some 18 to $19 \mathrm{~cm}$ behind the sputter cone.

A drawing of our ion source test facility is shown in figure 4, the most important component of which is a $30 \mathrm{~cm}$ radius double-focussing $90^{\circ}$ analyzing magnet. 


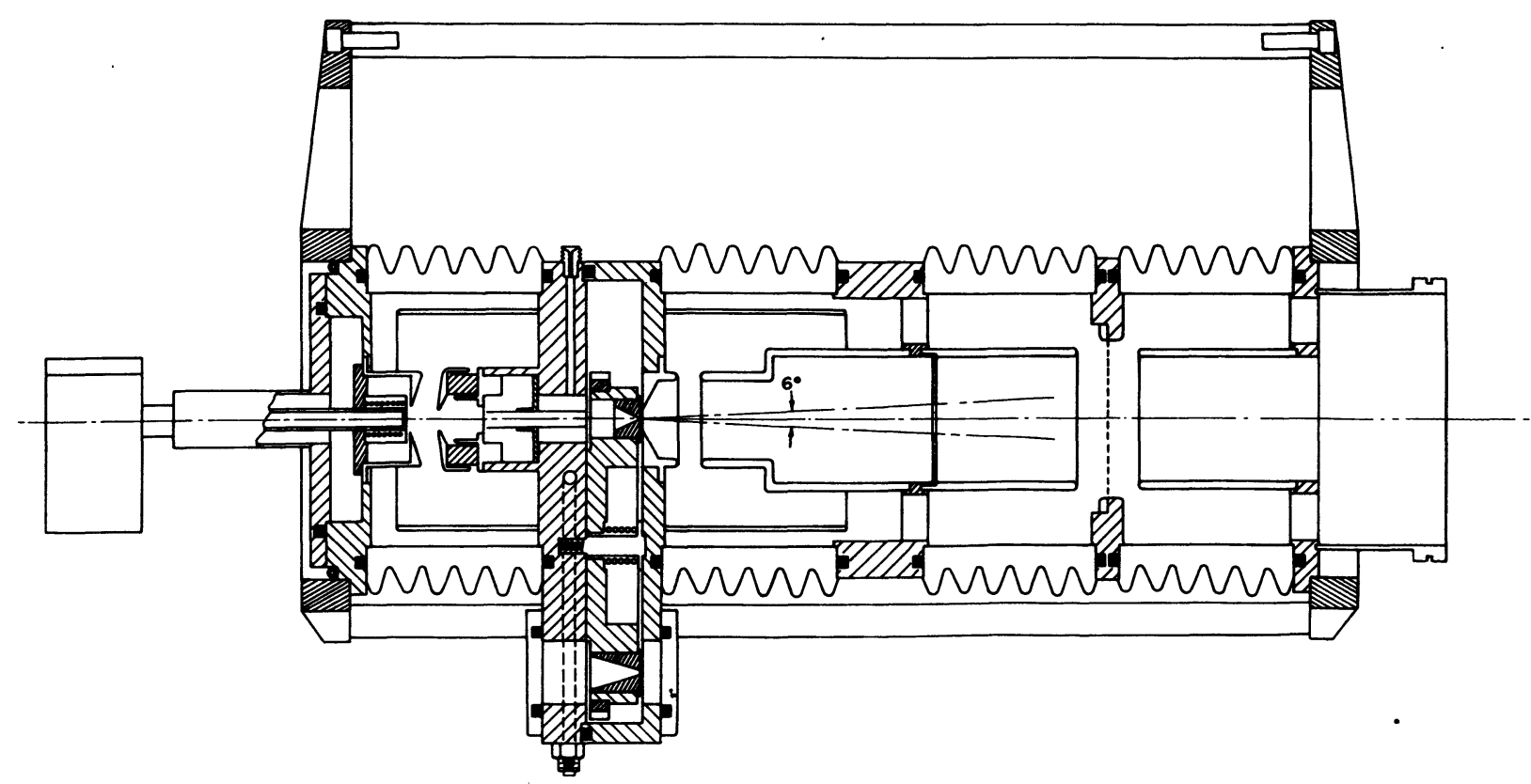

Fig. 3. - The caesium beam sputter source currently in use at the University of Pennsylvania. A source of this type was recently used to accelerate tritium.

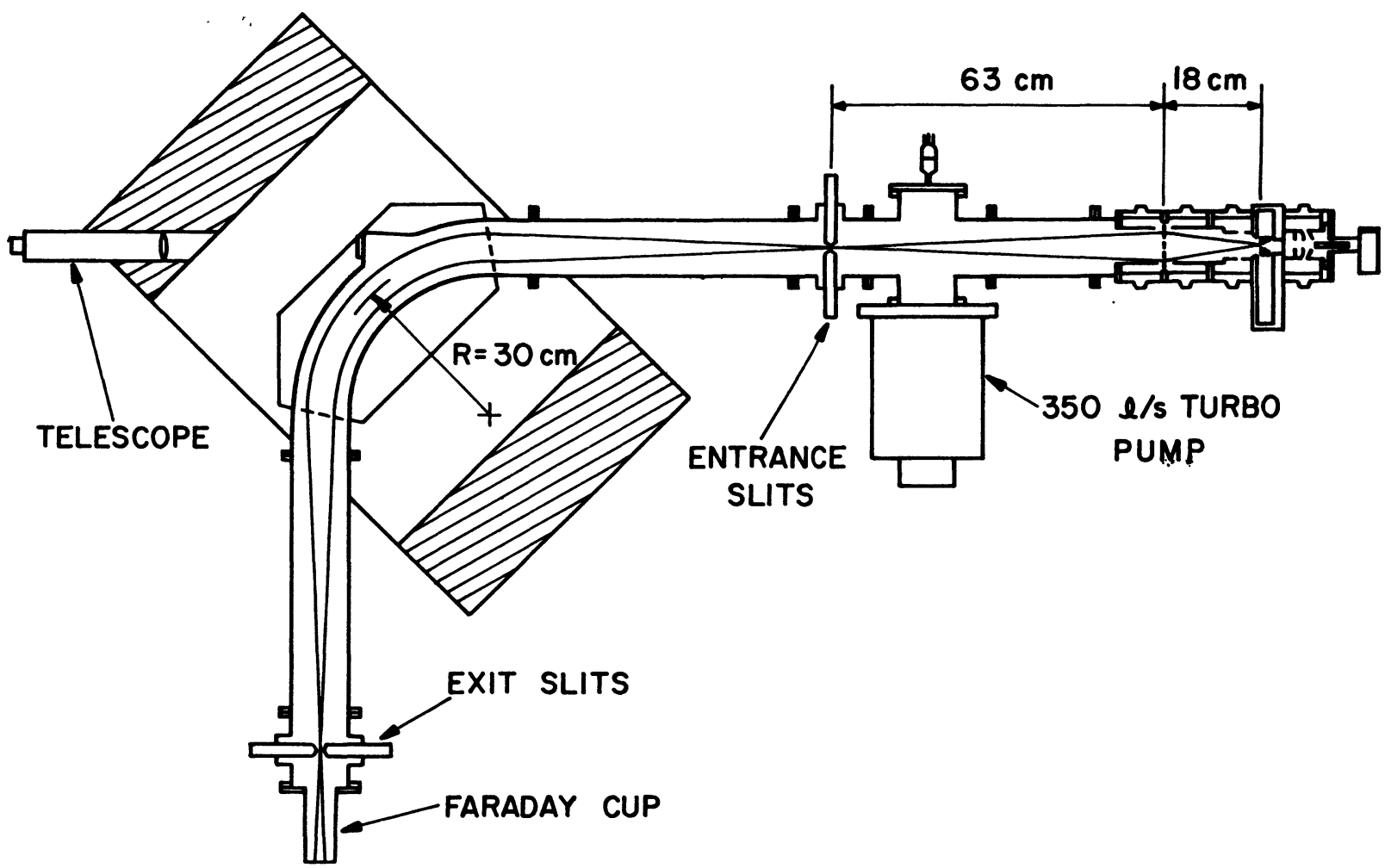

FIG. 4. - The University of Pennsylvania ion source test facility.

All of the negative ion currents that are subsequently quoted were measured or normalized to the entrance and exit slits being set at $\pm 3.8 \mathrm{~mm}$ - this corresponds to a system acceptance of $8 \mathrm{~mm} . \operatorname{mrad}$. MEV $1 / 2$ at $20 \mathrm{keV}$. Some of the spectra shown in the figures were measured with the slits set at $\pm 0.6 \mathrm{~mm}$ in order to improve the mass resolution $\Delta \mathrm{m} / \mathrm{m}$ to about $1 / 250$ and the indicated currents are correspondingly low.
Figure 5 shows some of the cone shapes used in the present investigation. A few attempts were made to optimize the shape of a cone but frequently this was determined by the material at hand or by convenience and consequently many of the quoted currents are far from optimum values. In the few cases where the influence of the cone shape was studied it was generally observed that shape $5 \mathrm{a}$ was best for materials 


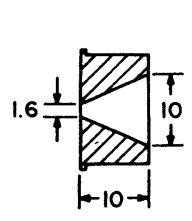

a

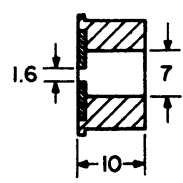

e

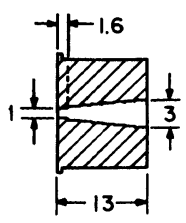

b

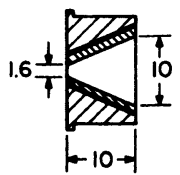

$f$
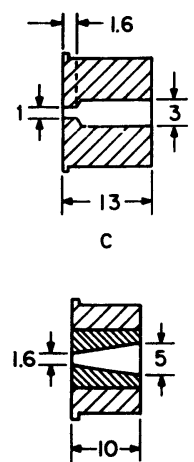
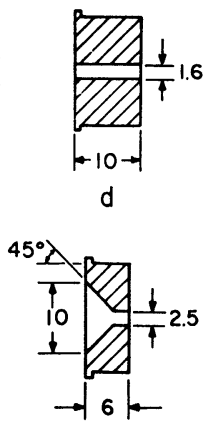

Fig. 5. - Some of the cone shapes used in the present study. All dimensions are in $\mathrm{mm}$.

that are difficult to sputter and that shape $5 \mathrm{~b}$ was significantly better with materials that sputter readily. For example, the most current that could be obtained from a copper cone of shape $5 \mathrm{a}$ was $2 \mu \mathrm{A}$ whereas a cone having shape $5 \mathrm{~b}$ yielded $7 \mu \mathrm{A}$.

It was frequently observed that after a few hours of use a cone would develop a remarkably small diameter $(<0.5 \mathrm{~mm})$ steep conical pit on its back surface presumably caused by the reflected caesium beam. To test the efficacy of the reflected beam as a source of negative ions two cones were fabricated similar to that shown in figure 6 , one with a strip of graphite and the other with a strip of silicon. These performed reasonably well, the former yielding about $20 \mu \mathrm{A}$ of $\mathrm{C}^{-}$and the latter $9 \mu \mathrm{A}$ of $\mathrm{Si}^{-}$. Applying a positive bias to the normally grounded negative ion extraction electrode significantly increased the currents and at $+2.5 \mathrm{kV}$ these were respectively 48 and $27 \mu \mathrm{A}$.

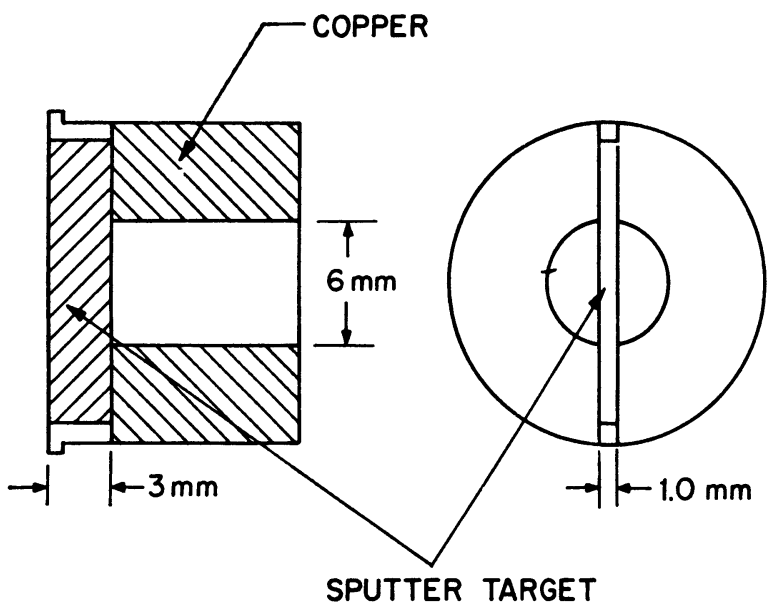

FIG. 6. - A drawing of the strip cone that was investigated with carbon and silicon. Most of the caesium beam, which travels from right to left, passes through the $6 \mathrm{~mm}$ aperture and is reflected by the positively biased negative ion extraction electrode. The reflected caesium beam is extremely well focussed and sputters a small region around the center of the strip.

Table I summarized our results for group I through VII of the periodic table as they stood about 4 months ago. With the exception of lithium the alkali metals remain a challenge and a recent attempt to make $\mathrm{Na}^{-}$from a cone made from a sodium-bismuth alloy ( $1: 1.8$ atomic ratio) yields only $13 \mathrm{nA}$ rising to $25 \mathrm{nA}$ with the application of an oxygen spray. An interesting and hitherto unreported result was the observation of 0.1 to $0.25 \mu \mathrm{A}$ beam of $\mathrm{CsC}_{4}{ }^{-}$and $\mathrm{CsC}_{6}$ - from a graphite cone - a spectrum showing these peaks is presented in figure 7 .

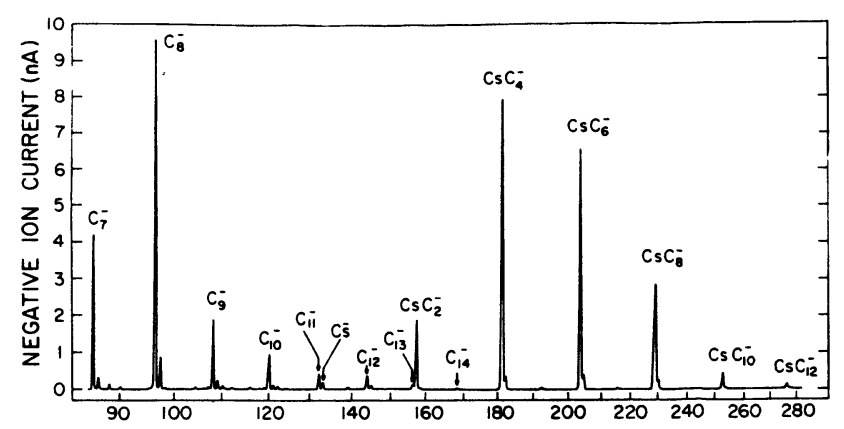

Fig. 7. - A portion of a spectrum obtained with a graphite cone showing prominent peaks corresponding to $\mathrm{CsC}_{4}{ }^{-}$and $\mathrm{CsC}_{6}^{-}$.

Until recently it appeared that the most suitable group II ion for acceleration was the oxide but the chance discovery [8] that an ammonia spray enables about $1 \mu \mathrm{A}$ beams of hydrides to be generated significantly changes the situation. Group III elements also prolifically form oxide negative ions and recently we tried ammonia spraying on aluminium. On our first attempt we obtained $0.8 \mu \mathrm{A}$ of $\mathrm{AlH}_{2}^{-}$and later under improved conditions were able to increase this to $1.8 \mu \mathrm{A}$. A typical aluminium spectrum obtained while spraying ammonia is shown in figure 8 . It remains to be seen if ammonia will be as equally effective with the other elements of this group.

Group IV is perplexing since carbon and silicon

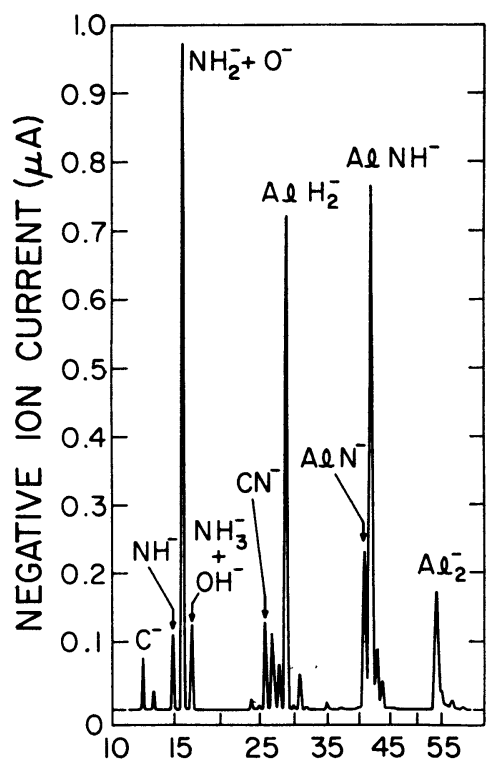

FIG. 8. - Negative ion spectrum obtained while spraying an aluminium cone with ammonia. A strong peak corresponding to $\mathrm{AlH}_{2}{ }^{-}$is clearly evident. 
TABLE I

\begin{tabular}{|c|c|c|c|c|c|c|}
\hline 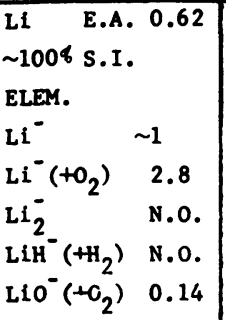 & $\begin{array}{ll}\left.\mathrm{Be}^{11}\right) \text { E.A. }<0 \\
100 \% \\
\text { ELEM. } \\
\mathrm{Be}^{-} \\
\mathrm{BeH}^{-1}\left(+\mathrm{H}_{2}\right) & \text { N.0. } \\
\mathrm{BeH}^{-}\left(\mathrm{NHH}_{3}\right) & 0.5\end{array}$ & 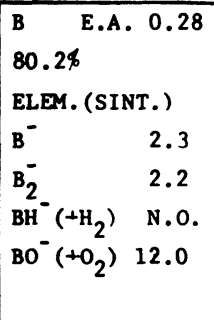 & $\begin{array}{|lrl|}\text { C } & \text { E.A. } & 1.27 \\
98.9 \% & & \\
\text { GRAPHITE } & \\
\mathrm{C}^{-} & >50 \\
\mathrm{C}_{2}^{-} & >30\end{array}$ & $\begin{array}{lr}\mathrm{N} & \text { E.A. }<0 \\
99.6^{4} & \\
\mathrm{Mg}^{-}+\mathrm{NH}_{3} & \\
\mathrm{~N}^{-} & \mathrm{N} .0 . \\
\mathrm{NH}^{-} & 0.7 \\
\mathrm{NH}_{2}^{-} & \sim 1.0\end{array}$ & $\begin{array}{lr}0 & \text { E.A. } 1.46 \\
99.8 \% & \\
\mathrm{~T}^{\mathrm{i}+\mathrm{O}_{2}} & \\
\mathrm{O}^{-} & >50 \\
\mathrm{O}_{2}^{-} & \sim 1.0 \\
0_{3}^{-} & \text {N.o. }\end{array}$ & $\begin{array}{lll}\mathrm{F} & \text { E.A. } & 3.40 \\
100 \% & \\
\mathrm{~T}^{\mathrm{i}+\mathrm{SF}_{6}} & \\
\mathrm{~F}^{-} & >50\end{array}$ \\
\hline $\begin{array}{ll}\mathrm{Na} & \text { E.A. } 0.55 \\
1008 & \end{array}$ & $\begin{array}{ll}\mathrm{Mg} \quad \mathrm{E} . \mathrm{A} .<0 \\
78.78 \\
\text { ELEM. } \\
\mathrm{Mg}^{-} & \\
\mathrm{MgH}^{-}\left({ }^{-} \mathrm{H}_{2}\right) & \mathrm{N} .0 . \\
\mathrm{MgH}^{-}\left(\mathrm{NHH}_{3}\right) & 0.5 \\
\mathrm{MgH}_{3}^{-}\left(+\mathrm{NH}_{3}\right) & 1.65 \\
\mathrm{MgO}^{-}\left(+\mathrm{O}_{2}\right) & 1.05\end{array}$ & 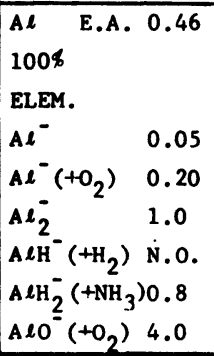 & $\begin{array}{lrl}\mathrm{Si} & \text { E.A. } & 1.39 \\
92.2 \varnothing & \\
\text { ELEM STRIP) } \\
\mathrm{Si}^{-} & 27.0 \\
\mathrm{Si}_{2}^{-} & 9.0\end{array}$ & \begin{tabular}{|lr}
$\mathrm{P}^{11}$ ) & E.A. 0.74 \\
1004 & \\
$\mathrm{GaP}$ & \\
$\mathrm{P}^{-}$ & 0.6 \\
\end{tabular} & 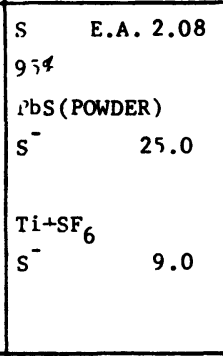 & $\begin{array}{ll}\mathrm{Cl} \quad \text { E.A. } 3.62 \\
75.54 \\
\mathrm{Ti}^{\mathrm{i}+\mathrm{C}} \mathrm{C}_{2} \mathrm{HCl}_{3} \\
\mathrm{Cl}^{-} \stackrel{25}{\sim}\end{array}$ \\
\hline $\begin{array}{ll}K & \text { E.A. } 0.50 \\
9.38 & \end{array}$ & $\begin{array}{ll}\mathrm{Ca} & \text { E.A. }<0 \\
978 & \\
\text { ELEM. } & \\
\mathrm{Ca}^{-} & \text {N.O. } \\
\mathrm{CaH}^{-}\left(+\mathrm{H}_{2}\right) & \text { N.0. } \\
\mathrm{CaH}^{-}\left(\mathrm{NHH}_{3}\right) & 0.6 \\
\mathrm{CaH}_{3}^{-}\left(\mathrm{NHH}_{3}\right) & 0.6 \\
\mathrm{CaO}^{-}\left(+\mathrm{O}_{2}\right) & 0.34\end{array}$ & $\begin{array}{l}\text { Ga } \quad \text { E.A. }<0 \\
60.4 \%\end{array}$ & $\begin{array}{lll}\text { Ge } & \text { E.A. } & 1.2 \\
36.5 \% & \\
\text { ELEM. } & \\
\mathrm{Ge}^{-} & 1.1 \\
\mathrm{Ge}_{2}^{-} & 0.5\end{array}$ & 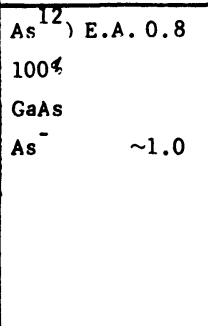 & $\begin{array}{lr}\mathrm{Se}^{16} \text {, E.A. } & 2.02 \\
\mathrm{CdSe}^{-} & \\
\mathrm{Se}^{-} & 7.0\end{array}$ & $\begin{array}{l}\mathrm{Br}^{11} \text { ) E.A. } 3.36 \\
50.5 \% \\
\mathrm{NaBr} \text { (POWDER) } \\
\mathrm{Br}^{-} \quad 5.0\end{array}$ \\
\hline $\begin{array}{ll}\text { Rb } & \text { E.A. } 0.49 \\
728 & \end{array}$ & $\begin{array}{l}\text { Sr E.A. }<0 \\
82.6 \%\end{array}$ & 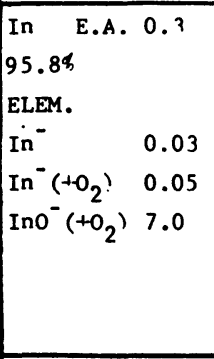 & $\begin{array}{lll}\mathrm{Sn} & \text { E.A. } & 1.25 \\
33{ }^{2} & & \\
\text { ELEM. } & \\
\mathrm{Sn}^{-} & & \\
\mathrm{Sn}^{-}\left(\mathrm{CO}_{2}\right) & 0.03 \\
\mathrm{Sn}_{2}^{-} & 0.05 \\
\mathrm{SnH}^{-}\left(+\mathrm{H}_{2}\right) & \mathrm{N} .0 . \\
\mathrm{SnO}^{-}\left(\mathrm{CO}_{2}\right) & 0.02 \\
\mathrm{SnO}_{2}^{-}\left(+\mathrm{O}_{2}\right) & 0.12 \\
\end{array}$ & 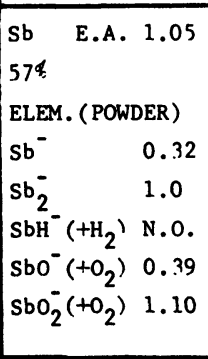 & 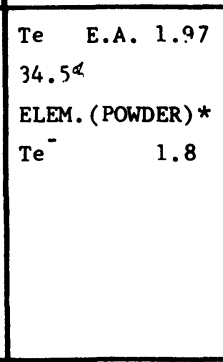 & 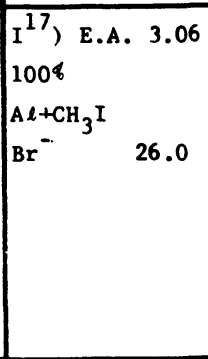 \\
\hline 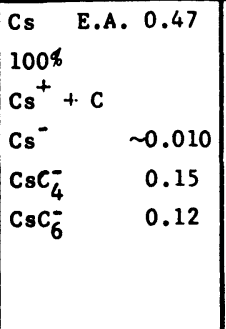 & $\begin{array}{ll}\mathrm{Ba} & \text { E.A. }<0 \\
71.74\end{array}$ & $\begin{array}{l}\text { Tl E.A. } 0.3 \\
70.58\end{array}$ & $\begin{array}{ll}\mathrm{Pb} & \text { E.A. } 1.1 \\
52.39 & \\
\text { ELEM. } & \\
\mathrm{Pb}^{-} . & 0.075 \\
\mathrm{~Pb}^{-}\left(+\mathrm{O}_{2}\right) & 0.110 \\
\mathrm{PbH}^{-}\left(+\mathrm{H}_{2}\right) & \mathrm{N} .0 . \\
\mathrm{PbO}^{-}\left(+\mathrm{O}_{2}\right) & 0.15 \\
\mathrm{PbO}_{2}\left(\mathrm{CO}_{2}\right) & 0.20\end{array}$ & $\begin{array}{l}\text { Bi } \\
100 \%\end{array}$ & Po E.A. 1.9 & E.A. 2.8 \\
\hline
\end{tabular}

form copious negative ion beams while heavier members such as tin and lead are among the most difficult negative ions - this in spite of them all having comparable electron affinities.

Since table I was prepared we have made some additional measurements on the group $\mathrm{V}$ elements. Recently, while accelerating $\mathrm{NH}^{-}$and $\mathrm{NH}_{2}^{-}$, it was verified that the latter is about 3 times more intense than the former. This was previously suspected but owing to the impossibility of distinguishing between
$\mathrm{O}^{-}$and $\mathrm{NH}_{2}^{-}$on the ion source test facility was never verified. Some comparative measurements have also been made using identically shaped cones of bismuth and a bismuth-sodium alloy (1.8:1 atomic ratio). The alloy cone yielded about $50 \%$ more $\mathrm{Bi}^{-}$than the pure metal. In both cases the $\mathrm{Bi}^{-}$current was largest while oxygen spraying and in the case of the alloy attained a maximum value of $0.8 \mu \mathrm{A}$. The results of similar measurements with lithium-lead and lithium-calcium cones were disappointing. The yield for all three 
elements was substantially lower than had been previously obtained from cones made from the element alone.

Owing to the large electron affinities of the group VI and VII elements fairly large currents are readily obtainable using a variety of techniques. These will not be discussed further here but it is worthy of comment that some of the methods indicated in table I could well be improved upon.

Table II shows the present results for the transition elements. A perusal of the table reveals that these elements show considerable diversity of behaviour. However, the $1 \mu \mathrm{A}$ plus goal appears obtainable for the elements in the columns below iron, cobalt, nickel and copper with the possible exceptions of iron and palladium which have anomalously low electron affinities. For the elements in the columns to the left of iron the situation leaves much to be desired and we failed to observe any elemental negative ion current exceeding $0.1 \mu \mathrm{A}-$ frequently $<10 \mathrm{nA}$. The situation improves if a molecular ion such as a hydride, a nitride or an oxide - particularly the latter - is acceptable. The same applies to the column headed by zinc, the elements of which all have negative electron affinities.

The complexity of the negative ion spectra of some of the transition elements is well illustrated in figure 9 which shows a negative ion spectrum from tantalum. Fortunately nitrogen or oxygen spraying causes a metamorphosis and, in the case of nitrogen, essentially one strong peak remains corresponding to $\mathrm{TaN}^{-}$. Oxygen produces 3 oxide peaks and the strongest $(6 \mu \mathrm{A})$ was $\mathrm{TaO}_{2}^{-}$.

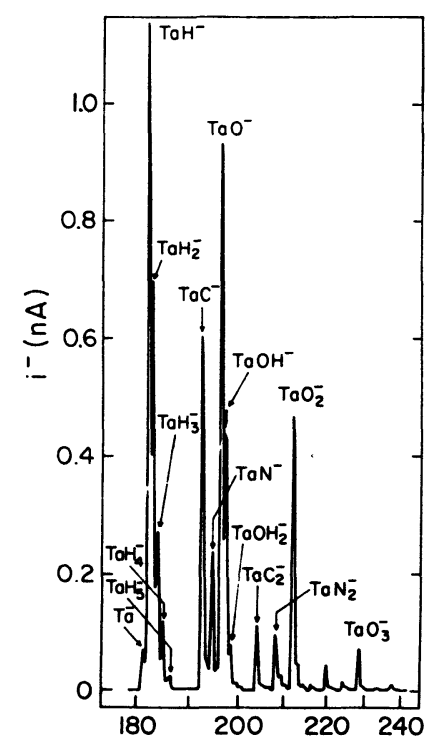

Fig. 9. - The extremely complex negative ion soectrum of tantalum.

Table III shows the scant data that we have so far obtained for the rare earths and actinides. In spite of the poor statistics it is likely that the elemental negative ion yields are going to be very small for all of these. The situation with the hydrides looks a little better but there is a possibility that ammonia may prove much more effective than hydrogen in forming these - we have not tried this. By far the most promising negative ions appear to be in the form of oxides with the exception of uranium where a strong nitride beam was observed.

5. Tritium Acceleration. - Figure 10 shows a schematic drawing of the tritium ion source system that we installed on our FN tandem accelerator last December and which became operational in February of this year. As was mentioned earlier the sputter source was the same as that shown in figure 3 and contained 6 cones - two containing hydrogen, one deuterium (each identical with the tritium cones), a graphite cone and two cones loaded with tritium. The hydrogen and deuterium cones were included to assist with alignment and to check the transmission through the accelerator and the graphite cone to provide a $\mathrm{C}^{2+}$ beam having the same magnetic rigidity as the triton beam for testing quadrupole magnets, etc.

Figure 11 shows a drawing of the final version of the tritium cone. The unusual shape of the tritium carrying titanium insert was arrived at after numerous

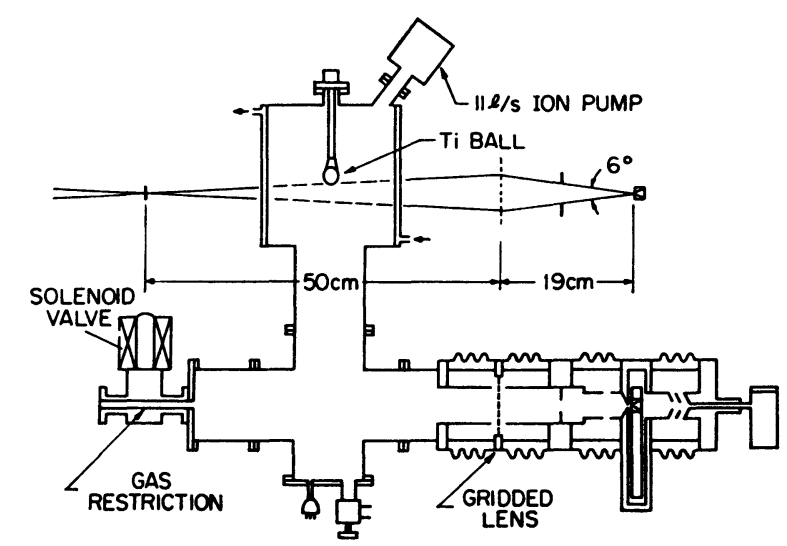

FIG. 10. - A schematic drawing of the ion source system that was recently used at the University of Pennsylvania for the acceleration of tritium.

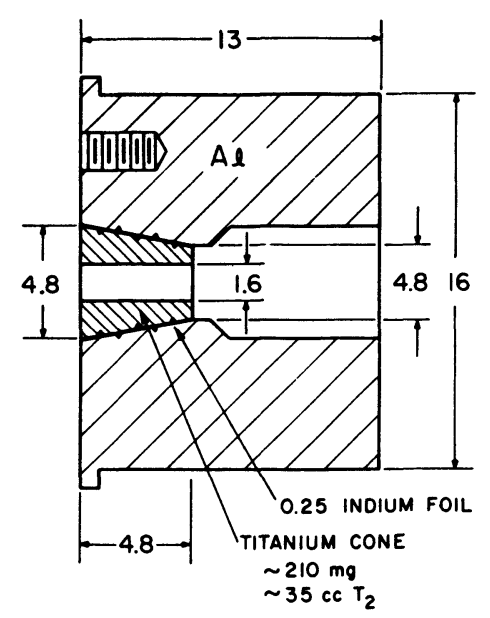

FIG. 11. - The titanium-tritium sputter cone. 


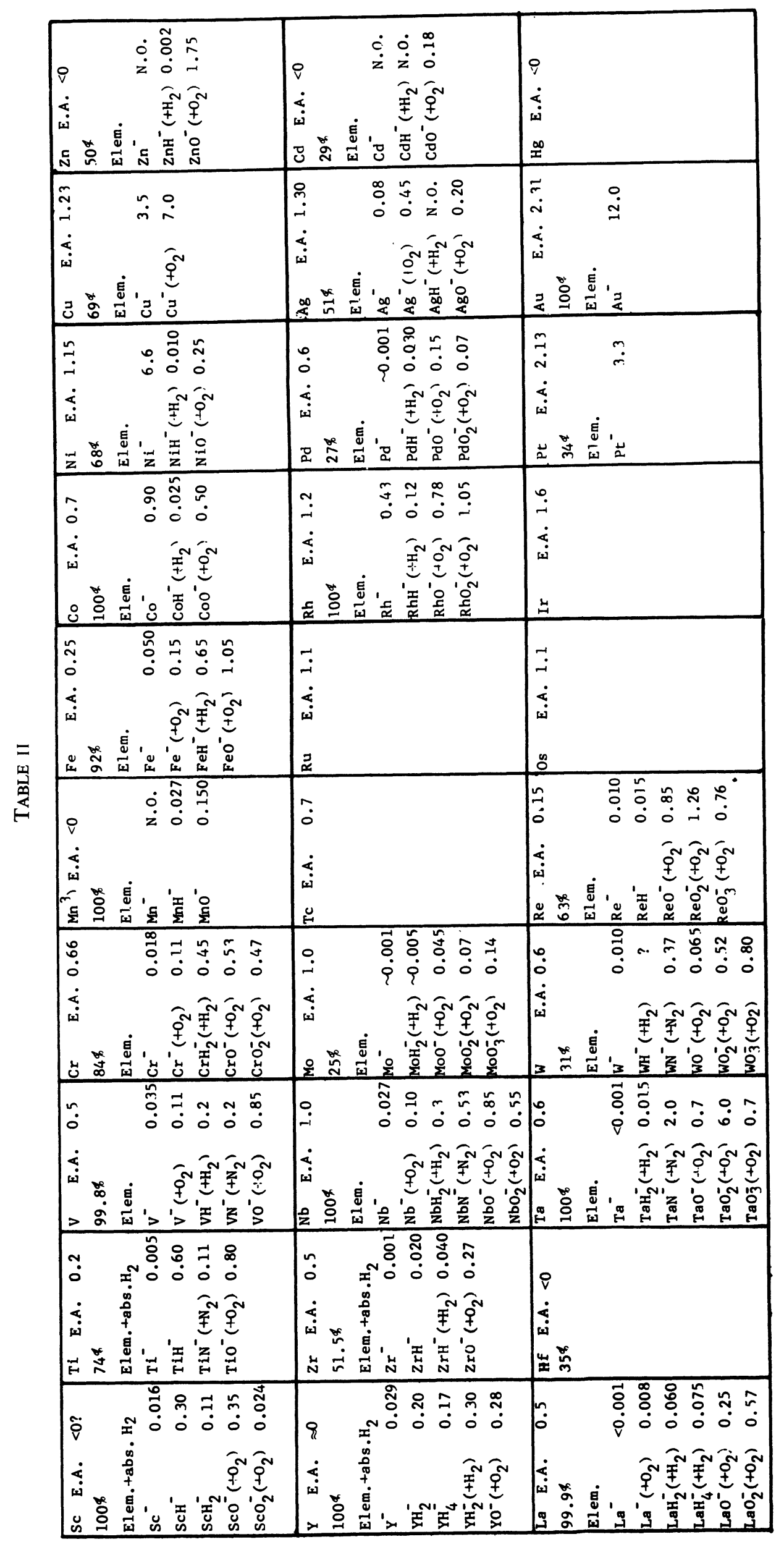




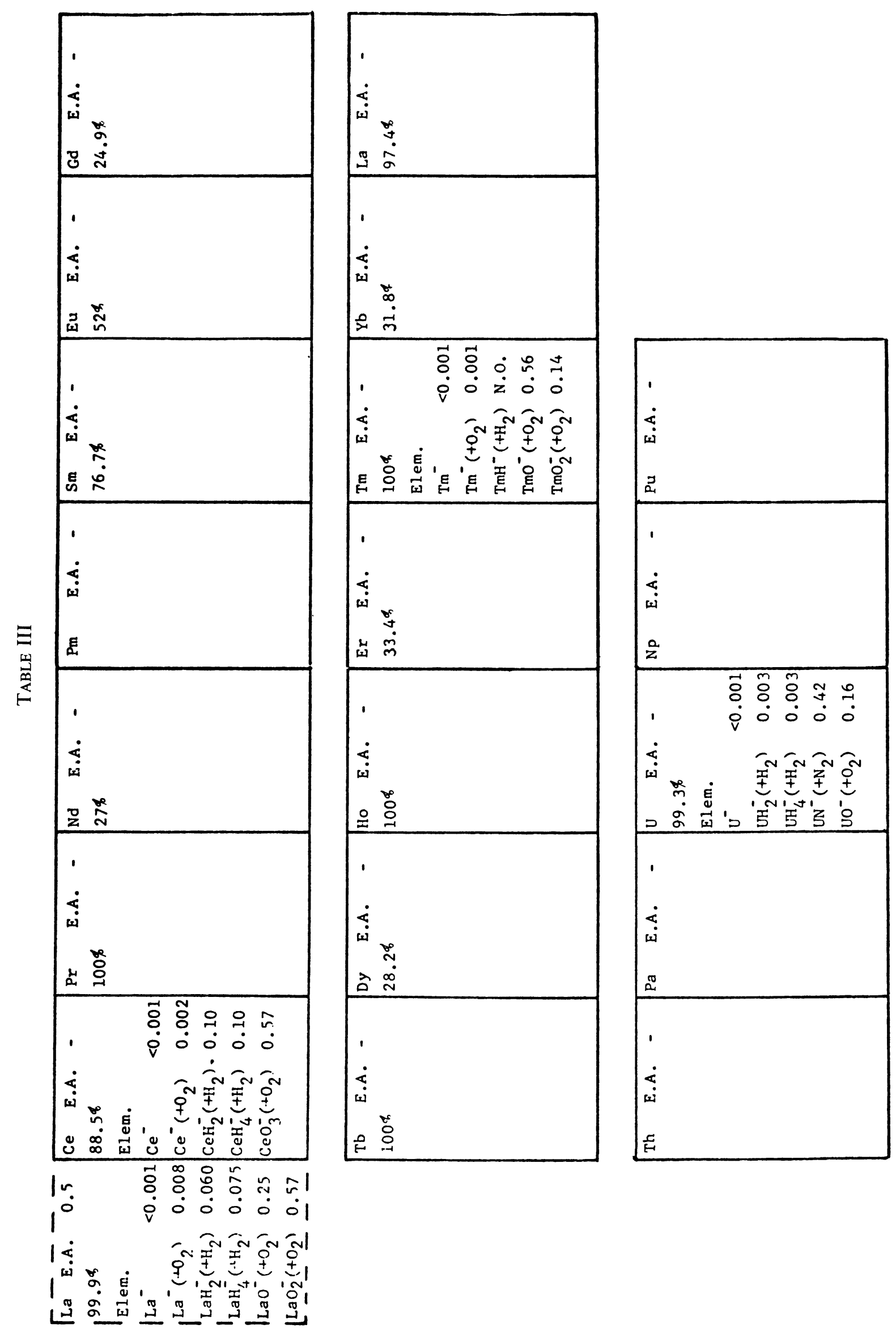


tests had been made with various shaped pieces of titanium loaded with deuterium and was adopted only after it had been demonstrated that this was capable of yielding a mean current of $2 \mu \mathrm{A}$ over a 250 hour period. These endurance tests were made with the same system (Fig. 10) that was later transferred to the tandem and also served to check the integrity of the interlocks, the effectiveness of the gas impedance tube isolating the source from the accelerator, the proper functioning of the isolation valve and to generally test the Ti-Ball pumping system. During these a quadrupole mass spectrometer was used to constantly monitor the residual vacuum and figure 12 shows a typical residual gas spectrum obtained with the source in operation. The partial pressure of deuterium in the source was estimated to be $4 \times 10^{-8}$ torr but this includes no corrections for the response of the mass spectrometer. It is noteworthy that all of the peaks containing deuterium vanished within minutes after rotating the deuterium cone out of the caesium beam indicating that desorption at room temperature was very small.

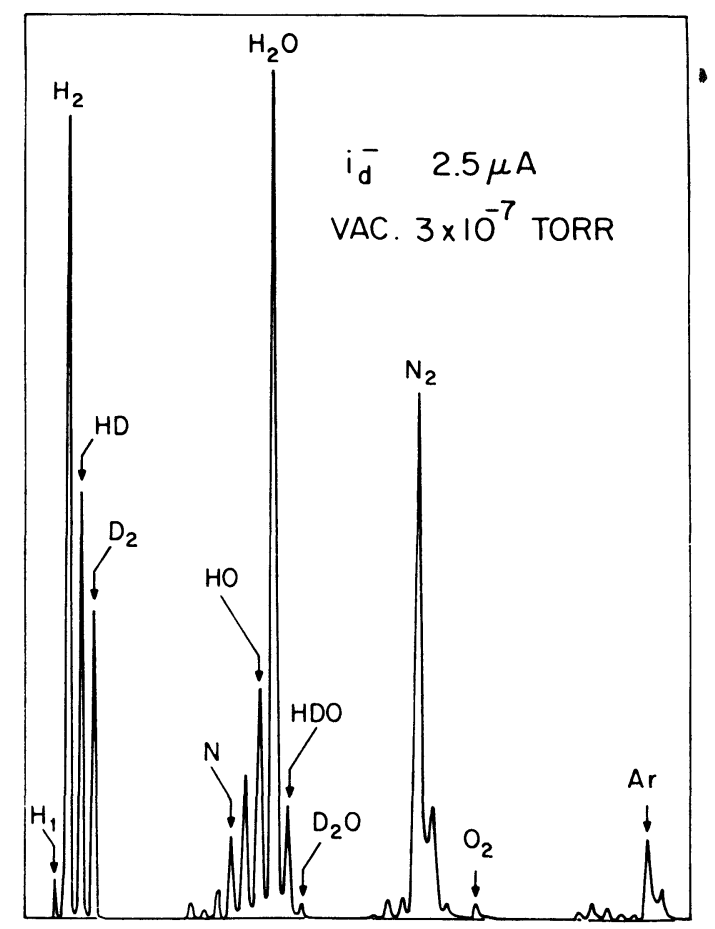

Fig. 12. - A residual gas spectrum obtained while the source system was being tested with a deuterium sputter cone.

The two titanium inserts were loaded with about $35 \mathrm{cc}$ of tritium and pressed into their indium-lined aluminium jackets by the U.S. Radium Corporation (1). They performed a splendid service and it is with pleasure that we acknowledge the assistance and advice of Mr. McGraw. Owing to the uncertainty of how much tritium might be released from these bulk loaded specimens during transit and might prove

(1) U.S. Radium Corporation Bloomsburg, Penna. 17815 U.S.A. hazardous on opening, the vacuum tight container shown in figure 13 was fabricated. The two cones arrived in this but not under vacuum. The container was then connected to a previously evacuated 10 liter vessel (not the two 1 liter vessels shown in Fig. 13) and their contents shared. On opening the cone container a very small release of tritium was observed amounting to less than $30 \mu \mathrm{Ci} / \mathrm{m}^{3}$ which rapidly dispersed. The cones were then transferred into the source using specially designed tools and the latter was roughed to about $10^{-2}$ torr with a vented mechanical pump prior to valving off and switching on the Ti-Ball and later the ion pump.

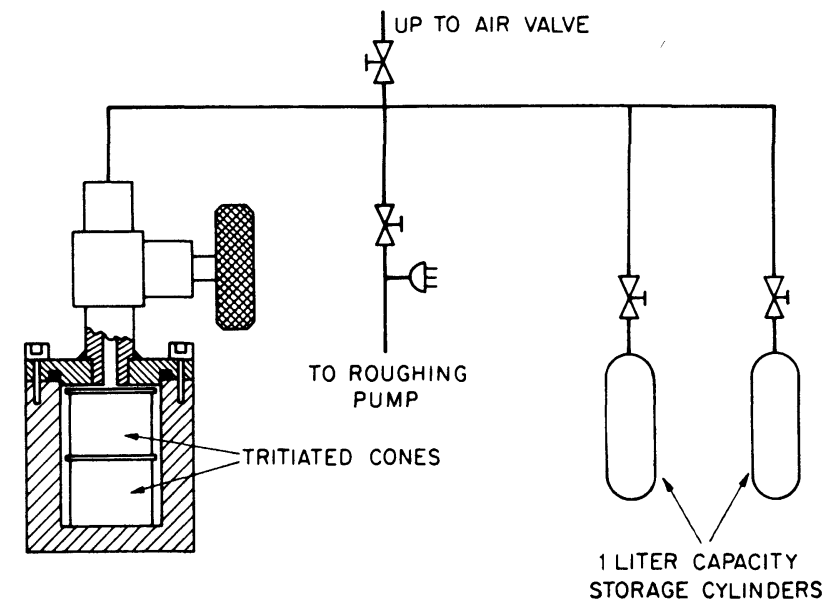

FIG. 13. - Showing the vacuum container that the tritium cones were transported in and the method by which it was evacuated prior to opening.

Figure 14 shows a highly schematic drawing of the source and injector system. It will be noticed that the source is at ground potential and that the injection energy is $20 \mathrm{keV}$. Transmission through the accelerator followed the pattern of earlier tests with hydrogen and deuterium and was $79 \%$ after allowance had been made for a $10 \%$ loss in the grid at the entrance to the accelerator tube. Carbon foil stripping was used, the terminal voltage was usually between 6 and 8.5 MV and the analyzed triton current between 0.25 and $1 \mu \mathrm{A}$. Transmission remained essentially constant over the first 350 hours of operation (the two tritium

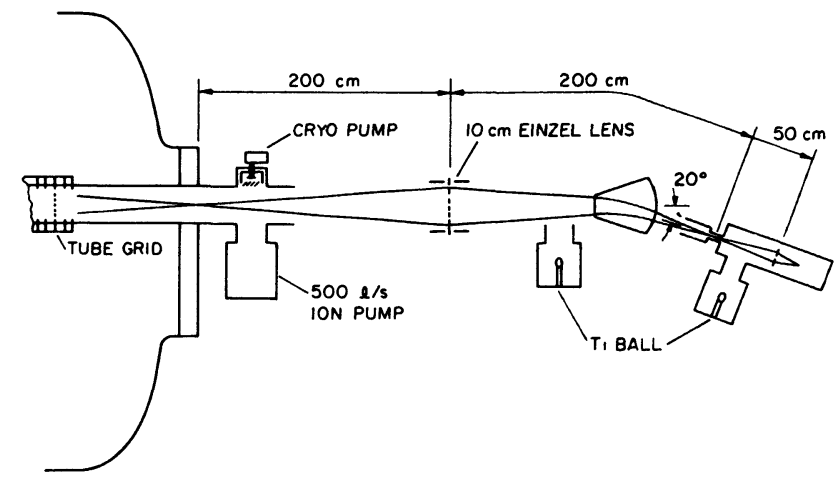

FIG. 14. - A schematic drawing of the University of Pennsylvania's tritium injector 
cones were frequently interchanged) and then gradually declined over the next 250 hours to about $33 \%$. Visual inspection of the cones revealed that the caesium beam was slightly off axis and that the initial $1.6 \mathrm{~mm}$ diameter cone aperture had been elongated into an asymmetric ellipse with a major axis of about $4 \mathrm{~mm}$. The loss in transmission efficiency could have been avoided in several different ways had it been anticipated but probably the simplest would have been to have used the same amount of tritium distributed in 5 or 6 cones having smaller titanium inserts.

The source operated very successfully for a period of 735 hours with no major difficulties and was still operational when it was removed from the accelerator - the time that tritium was accelerated was slightly less, approximately 600 hours. The mean negative current was about $1 \mu \mathrm{A}$ but this could be adjusted at will to well in excess of $2 \mu \mathrm{A}$. If it is assumed that half of the available tritium was used then the efficiency of producing negative tritons was about $0.7 \%$ - at least two orders of magnitude greater than that of a direct extraction duoplasmatron.

The entire source system, as depicted in figure 10, was removed under vacuum from the accelerator at the beginning of April and so far has not been disturbed. A number of wipes were counted from within the inflection magnet chamber and these indicated a contamination level of about 25 to $50 \mathrm{mCi}$. This was expected since it was anticipated that about $300 \mathrm{mCi}$ of tritium gas would escape through the gas impedance tube and it was to capture the bulk of this that a second Ti-Ball pump had been installed immediately after the magnet inflection chamber (see Fig. 13). After this Ti-Ball had been removed and capped for disposal more wipes. were taken in the region of the $10 \mathrm{~cm}$ gridded einzel lens. Gratifyingly these showed contamination only at a few $\mu \mathrm{Ci}$ level. At the present time the acceleration tubes have not yet been let up to air and consequently no wipes have been assayed but it is anticipated that contamination will be minor.

\section{References}

[1] Heinemeier J. and TYKeSSON P., Nucl. Instrum. Methods 141 (1977) 183.

[2] Heinemeier J. and Tykesson P., Revue Phys. Appl. 12 (1977).

[3] Heinicke E., Bethge K. and BaumanN H., Nucl. Instrum. Methods 58 (1968) 125.

[4] Tykesson P., ANDERSEN H. H. and Heinemeier J., IEEE Trans. Nucl. Sci. NS-23 (1976) 1104.
[5] Doucas G., Greenway T. J. L., Mck. Hyder H. R. and KNox A. B., IEEE Trans. Nucl. Sci. NS-23 (1976) 1155.

[6] Doucas G., MCK. Hyder H. R. and Knox A. B., Oxford University Report 19/75.

[7] Middleton R., IEEE Trans. Nucl. Sci. NS-23 (1976) 1098.

[8] Middleton R., Nucl. Instrum. Methods 141 (1977) 373. 